\title{
Muscarinic modulation of conductances underlying the afterhyperpolarization in neurons of the rat basolateral amygdala
}

\author{
Mark D. Womble and Hylan C. Moises \\ Department of Physiology, The University of Michigan Medical School, Ann Arbor, MI 49109-0622 (USA)
}

(Accepted 30 March 1993)

Key words: Amygdala; $\mathrm{K}^{+}$current; Carbachol; Afterhyperpolarization; Accommodation

\begin{abstract}
The excitability level of pyramidal neurons in the basolateral amygdala (BLA) is greatly increased following muscarinic receptor activation, an effect associated with an increased rate of action potential firing and reduction of the afterhyperpolarization (AHP). We impaled BLA pyramidal neurons in slices of rat ventral forebrain with a single microelectrode to examine the currents underlying the AHP and spike frequency accommodation and determine their sensitivities to muscarinic modulation. In voltage-clamp, depolarizing steps were followed by biphasic outward tail currents, consisting of rapidly decaying $\left(I_{\text {Fast }}\right)$ and slowly decaying $\left(I_{\text {Slow }}\right)$ current components. These corresponded temporally with the medium and slow portions of the AHP, respectively. The reversal potential for the $I_{\text {Fast }}$ component of the AHP tail current shifted in the depolarizing direction with increases in the extracellular $\mathrm{K}^{+}$concentration. The amplitude of $I_{\text {Fast }}$ was reduced during perfusion of 0 -Ca ${ }^{2+}$ medium or by superfusion of TEA $(1-5 \mathrm{mM})$ or carbachol $(10-40 \mu \mathrm{M})$. It is suggested that $I_{\text {Fast }}$ was produced by the rapidly decaying $\mathrm{Ca}^{2+}$-activated $\mathrm{K}^{+}$current $\left(I_{\mathrm{C}}\right)$ and the muscarinic-sensitive M-current $\left(I_{\mathrm{M}}\right)$. The $I_{\text {Slow }}$ tail current component reversed at the estimated values for $E_{\mathrm{K}}$ in medium containing either normal or elevated $\mathrm{K}^{+}$levels. This component was eliminated by perfusion of $0-\mathrm{Ca}^{2+}$ medium or inclusion of cyclic-AMP in the recording electrode. It was not blocked by TEA $(5 \mathrm{mM})$ or apamin $(50-500 \mathrm{nM})$, but was reduced by carbachol in a dose-dependent manner $\left(\mathrm{IC}_{50}=0.5 \mu \mathrm{M}\right)$. Electrical stimulation of cholinergic afferent pathways to the BLA produced inhibition of $I_{\text {Slow }}$, an effect which was enhanced by eserine and prevented by atropine. Loss of the $I_{\text {Slow }}$ component was always accompanied by similar reductions in accommodation and the slow AHP. It was concluded that this tail current component resulted from the slowly decaying $\mathrm{Ca}^{2+}$-activated $\mathrm{K}^{+}$ current, $I_{\mathrm{AHP}}$. Thus, the muscarinic inhibition of $I_{\mathrm{AHP}}$ contributes to the enhanced excitability exhibited by BLA pyramidal neurons following cholinergic stimulation.
\end{abstract}

\section{INTRODUCTION}

The basolateral nucleus of the amygdala (BLA) has been described as cortical-like in its cytoarchitecture ${ }^{7}$. In agreement with this, previous work from our laboratory has demonstrated that the major neuronal cell type of the rat BLA is a large, pyramidal projection neuron having many morphological and electrophysiological features similar to those seen in pyramidal neurons of the hippocampus and cerebral cortex ${ }^{29}$ (see also refs. 20,21). In our experiments, pyramidal neurons of the BLA characteristically had resting potentials near $-70 \mathrm{mV}$ and showed pronounced accommodation in the frequency of action potential firing during a prolonged pulse of depolarizing current. Prolonged depolarizations were followed by a prominent, biphasic afterhyperpolarization (AHP) that could be divided into 2 components, a rapidly decaying medium AHP (mAHP) with a time-course of tens to a few hundred milliseconds, followed by a long-lasting slow AHP (sAHP) that decayed over a period of several seconds ${ }^{29}$.

The biphasic AHP found in BLA pyramidal neurons closely resembles that exhibited by pyramidal neurons in the mammalian hippocampus. In this latter cell type, it has been determined that the mAHP results from the action of several potassium currents ${ }^{27,30}$, including a rapidly decaying $\mathrm{Ca}^{2+}$-activated $\mathrm{K}^{+}$current $\left(I_{\mathrm{C}}\right)^{1,6}$, the voltage-activated M-current $\left(I_{\mathrm{M}}\right)^{5,13}$ and a hyperpolarization-activated cation current $\left(I_{\mathrm{H}}\right)^{13}$. In contrast, the sAHP in hippocampal pyramidal neurons is produced by a single current, the slowly decaying $\mathrm{Ca}^{2+}$. activated $\mathrm{K}^{+}$conductance, $I_{\mathrm{AHP}}{ }^{17}$. The muscarinic inhibition of $I_{\mathrm{AHP}}$ in hippocampal neurons results in reductions of both the accommodation response during 
a prolonged depolarizing stimulus and the subsequent sAHP $3,9,10,18,19$.

The BLA receives an extensive cholinergic innervation arising from scattered populations of cholinergic cell bodies located within the nucleus basalis and adjacent regions of the ventral forebrain ${ }^{8,14}$. Stimulation of these cholinergic amygdalopetal inputs in slices of rat ventral forebrain or exogenous application of muscarinic agonists produces several changes in BLA pyramidal neurons, including a prolonged membrane depolarization associated with a decrease in membrane conductance and reductions of the accommodation response and $\mathrm{SAHP}^{29}$. These changes are associated with a greatly increased level of BLA neuronal excitability. We have previously shown that the muscarinic-induced membrane depolarization resulted from inhibitions of the $\mathrm{M}$-current and a voltage-insensitive $\mathrm{K}^{+}$leak conductance $^{32}$. In the present study, we used the singleelectrode voltage-clamp technique in combination with bath application of carbachol and stimulation of cholinergic afferents to the BLA to identify additional membrane conductances that contribute to production of spike frequency accommodation and the SAHP, and which serve as targets of muscarinic inhibition in BLA pyramidal neurons. Some of these results have appeared in abstract form ${ }^{22,31}$.

\section{MATERIALS AND METHODS}

The experiments were carried out using slices of rat ventral forebrain, prepared as previously described ${ }^{29.32}$. Briefly, adult male Sprague-Dawley rats (150-200 g; Charles River) were killed by decapitation and the brain rapidly removed to ice-cold artificial cerebrospinal fluid (ACSF), pregassed with $95 \% \mathrm{O}_{2} / 5 \% \mathrm{CO}_{2}$. The ACSF (pH 7.4) consisted of (in mM): $\mathrm{NaCl} 124 ; \mathrm{KCl} 3.5 ; \mathrm{CaCl}_{2} 3.0$; $\mathrm{MgSO}_{4} 1.5 ; \mathrm{NaH}_{2} \mathrm{PO}_{4} 1.0 ; \mathrm{NaHCO}_{3} 26.2 ;$ glucose 11.0. Horizontal slices of the ventral forebrain containing the BLA were cut at 500 $\mu \mathrm{m}$ using a Vibraslicer (World Precision Instruments) and transferred to a holding chamber containing room temperature ACSF continuously bubbled with $95 \% \mathrm{O}_{2} / 5 \% \mathrm{CO}_{2}$. Individual slices were transferred to a recording chamber as needed and held submerged with nylon netting under continuously flowing oxygenated ACSF. All experiments were performed at room temperature $\left(24^{\circ} \mathrm{C}\right)$. In some experiments, tetrodotoxin (TTX; $1 \mu \mathrm{M}$ ) was added to the perfusion medium prior to voltage-clamping to block action potential generation and eliminate spontaneous synaptic activity. In various experiments, carbachol (carbamylcholine chloride, 0.5-40 $\mu \mathrm{M}$ ), atropine sulfate $(1 \mu \mathrm{M})$, cesium chloride $(1 \mathrm{mM})$, cobalt chloride $(2 \mathrm{mM})$, cadmium chloride $(200 \mu \mathrm{M})$, tetraethylammonium chloride (TEA, $1-5 \mathrm{mM})$ or apamin $(50-500 \mathrm{nM})$ were added to the bathing medium. For preparation of calcium-free medium, $\mathrm{NaCl}$ was reduced to 118.5 $\mathrm{mM}$ and $\mathrm{CaCl}_{2}$ was replaced with $10 \mathrm{mM} \mathrm{MgSO}_{4}$. Test substances were dissolved in ACSF to their final concentration and applied to the slice by means of a multi-port valve system. All drugs were obtained from Sigma Chemical Co.

Pyramidal neurons within the BLA were impaled with a single microelectrode pulled from $1.2 \mathrm{~mm}$ o.d. capillary tubing (WP Instruments) and filled with a solution containing $2.7 \mathrm{M}$ potassium chloride and $0.4 \mathrm{M}$ potassium acetate, yielding electrode resistances of 30-100 $\mathrm{M} \Omega$. In some experiments, $100 \mathrm{mM}$ cyclic-AMP was also included in the electrode filling solution. Only cells with resting potentials more negative than $-55 \mathrm{mV}$ and overshooting action potentials greater than $70 \mathrm{mV}$ in height were included in this study. Intracellular discontinuous current-clamp and single-electrode voltage-clamp recordings were obtained using an Axoclamp $2 \mathrm{~A}$ amplifier with a $30 \%$ duty cycle, as described in Womble and Moises ${ }^{32}$. The sampling frequency in both modes was approximately $3.0 \mathrm{kHz}$. Amplified current and voltage signals were displayed on a storage oscilloscope, while a separate oscilloscope was used to continuously monitor the headstage output to verify that the voltage drop across the recording electrode had dissipated completely during the interval between current injection and voltage sampling. In voltage-clamp mode, gain settings of 3-8 $\mathrm{nA} / \mathrm{mV}$ produced clamp settling times of $\leqq 3 \mathrm{~ms}$. Voltage clamp records were discarded if the voltage response during the command pulse showed a sag of more than $1-2 \mathrm{mV}$ in the recorded membrane potential, indicating loss of voltage control. This problem was only encountered in some cells during the peak outward current elicited by a depolarizing voltage-step. The membrane potential actually recorded during the voltage step, rather than the designated command potential, is illustrated in all figures and was used for the construction of current-voltage relationships.

For all current-clamp experiments, the neuron was held at a constant membrane potential of $-60 \mathrm{mV}$ by application of steady DC current prior to action potential production. Similarly, $-60 \mathrm{mV}$ was used as the standard holding potential level in all voltage-clamp experiments, unless otherwise noted. The use of a standard membrane potential allowed for direct comparison of the AHP between cells and controlled for the voltage-dependent conductance changes which are normally associated with the depolarizing action of carbachol ${ }^{29,32}$. The level of $-60 \mathrm{mV}$ was chosen as a constant reference potential in order to enhance the AHP amplitude and to avoid activation of the $\mathrm{H}$-current ${ }^{13,26}$, an inward-going current which activates in BLA neurons with hyperpolarization below $-60 \mathrm{mV}^{22}$. In some experiments, the hybrid-clamp technique was utilized to evoke an AHP tail current ${ }^{17,19,24}$. In this technique, the cell was held at $-60 \mathrm{mV}$ in current-clamp mode prior to injection of a depolarizing current pulse to evoke a burst of action potentials. Upon termination of the current pulse, the amplifier was rapidly switched into voltage-clamp mode at a holding potential of $-60 \mathrm{mV}$ to record the currents underlying the AHP. Activation of cholinergic afferents in the slice was accomplished by brief tetanic stimulation of the substantia innominata or the external capsule, delivered via a bipolar stimulating electrode placed on the surface of the slice.

Current and voltage records were filtered at $300 \mathrm{~Hz}$ and collected for storage by microcomputer using pClamp software (Axon Instruments). The data records were analyzed off-line with DAOS software (Laboratory Software Associates, Vic., Australia) using a cursor controlled least-squares procedure for exponential curve fitting. The complex AHP tail current was separated into individual components using a curve 'peeling' technique. In this analysis, a single exponential curve was first fitted to the late, slowly decaying portion of the tail current, beginning approximately $300 \mathrm{~ms}$ after termination of the depolarizing voltage step, to obtain an estimate of the $I_{\text {Slow }}$ component. This curve was extrapolated back to the end of the preceding depolarizing step and then subtracted from the total tail current. A second exponential curve was fitted to the residual tail current to yield an estimate of the $I_{\text {Fast }}$ component. Peak amplitudes for each of these tail current components were obtained from the point at which the extrapolated exponential curves intersected the preceeding depolarizing voltage step (time 0 ).

Mean values are given in the text together with the S.E.M. The S.E.M. was also included as error bars with graph points that refer to the means of 3 or more measurements.

\section{RESULTS}

The data presented here were obtained from stable, long-term recordings in 97 BLA pyramidal neurons. These cells had a mean resting potential of $-68.6 \pm 0.5$ $\mathrm{mV}(n=97)$ and exhibited pronounced accommoda- 
tion in the rate of spike discharge during passage of a prolonged $(500 \mathrm{~ms})$ depolarizing current pulse through the recording electrode. In the vast majority of cases $(92 \%)$, termination of a current-evoked burst of action potentials was followed by a long-lasting, biphasic AHP which we have found to be characteristic of BLA pyramidal neurons ${ }^{29}$. In the example shown in Fig. 1A, a pyramidal neuron was held in current-clamp mode at a membrane potential of $-60 \mathrm{mV}$ by the application of steady DC current. Passage of a $500 \mathrm{~ms}$ depolarizing current pulse $(0.5 \mathrm{nA})$ through the recording electrode caused the cell to fire an initial burst of action potentials at high frequency followed by a gradual decrease in the rate of spike firing. Termination of the current pulse revealed a prolonged AHP that decayed over a period of several seconds. It was possible by visual inspection to resolve the AHP into 2 distinct components, a medium-duration mAHP, lasting for approximately $200 \mathrm{~ms}$, followed by a slowly decaying sAHP that persisted for over 3 seconds.

After a series of current-evoked afterhyperpolarizations had been recorded in normal medium, the cell was voltage-clamped at a holding potential of $-60 \mathrm{mV}$ (Fig. 1B). Stepping the neuron to $-30 \mathrm{mV}$ for $900 \mathrm{~ms}$ resulted in a brief inward current in the absence of
TTX, followed by activation of an increasingly large outward current which corresponded temporally with the development of the accommodation response seen in the unclamped neuron. Termination of the depolarizing voltage step revealed a long-lasting, outward tail current, with a rapidly decaying portion that corresponded in duration to the mAHP and a slowly decaying segment that showed a close temporal correspondence with the occurrence of the sAHP. Plotting tail current amplitude as a function of time on a semilogarithmic scale (Fig. 1C, circles) revealed that the tail current could be separated into 2 current components, each of which decayed along a single exponential time-course. We have designated the initial, rapidly decaying tail current component as $I_{\text {Fast }}$, and the later, slowly decaying component as $I_{\text {Slow }}$. In the neuron shown in Fig. 1, $I_{\text {Fast }}$ had a time 0 peak amplitude of $224 \mathrm{pA}$ and decayed with a tau of $151 \mathrm{~ms}$, while $I_{\text {Slow }}$ had a time 0 peak amplitude of $72 \mathrm{pA}$ and a decay tau of $1,638 \mathrm{~ms}$. Overall, tail currents recorded upon returning to a holding potential of $-60 \mathrm{mV}$ following a $900 \mathrm{~ms}$ depolarizing voltage step showed an $I_{\text {Fast }}$ component with an average peak amplitude of $165 \pm 11 \mathrm{pA}$ and a decay tau of $138 \pm 9 \mathrm{~ms}(n=77)$. The $I_{\text {Slow }}$ tail current component of BLA pyramidal neurons had a
A

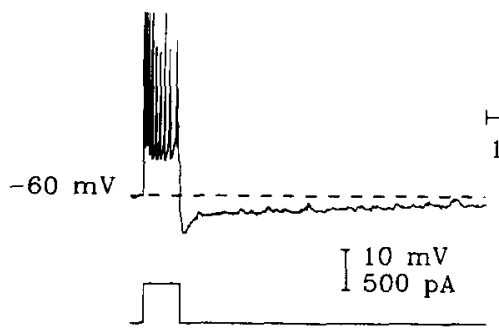

B

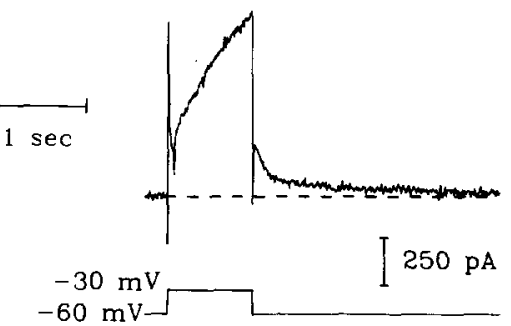

$\mathrm{C}$

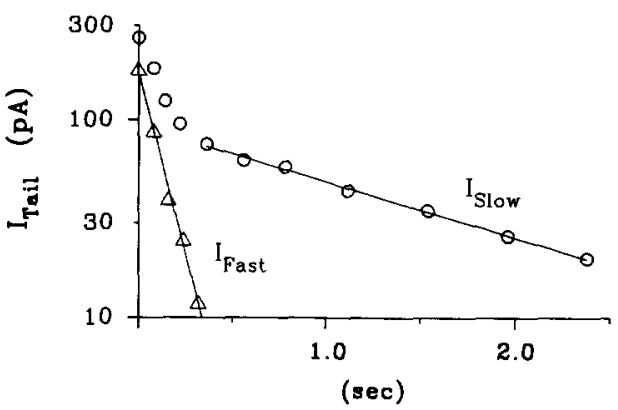

Fig. 1. The AHP and its underlying currents. A: current-clamp record obtained in normal medium from a pyramidal neuron held at $-60 \mathrm{mV}$ by the application of steady DC current. The resting potential prior to application of DC current was $-68 \mathrm{mV}$. Passage of a $500 \mathrm{~ms}$ depolarizing current pulse $(0.5 \mathrm{nA})$ evoked a series of action potentials the rate of firing of which accommodated with time. Termination of the current pulse revealed the presence of a prolonged biphasic AHP, consisting of medium and slow components. Action potentials were truncated by the digitization process. B: voltage-clamp record obtained from the same neuron in the absence of TTX. Application of a $900 \mathrm{~ms}$ voltage step to -30 $\mathrm{mV}$ from a holding potential of $-60 \mathrm{mV}$ activated a brief inward current and then an increasingly large outward current. This was followed upon termination of the step by a prolonged, biphasic tail current. The durations of the rapidly and slowly decaying components of the tail current corresponded with the durations of the $\mathrm{mAHP}$ and sAHP, respectively. $\mathrm{C}$ : semi-logarithmic plot of the total tail current (O) recorded in B as a function of time. The late portion of the tail current showed a slow rate of decay that followed a single exponential time-course $\left(I_{S l o w}\right)$. Extrapolation and subtraction of this curve from the total current allowed for the isolation of a rapidly decaying current component ( $\left.I_{\text {Fast }}\right)$, which also followed a single exponential time-course $(\Delta)$. 
peak amplitude of $106 \pm 12 \mathrm{pA}$ and displayed a much slower mean rate of decay $(2,030 \pm 197 \mathrm{~ms}, n=71)$.

Reversal potentials of $I_{\text {Fast }}$ and $I_{\text {Slow }}$

The reversal potentials $\left(E_{\mathrm{Rev}}\right)$ for the rapidly and slowly decaying components of the tail current were determined to characterize the ionic basis for $I_{\text {Fast }}$ and $I_{\text {Slow }}$. During these measurements, $\mathrm{Cs}^{+}(1 \mathrm{mM})$ was included in the bathing saline to prevent contamination of the tail current by the H-current, a voltage-activated inward current that develops during hyperpolarizations beyond $-60 \mathrm{mV}^{13,22}$. The protocol used for determination of $E_{\mathrm{Rev}}$ is illustrated in Fig. 2A. In this experiment, a pyramidal neuron in normal ACSF containing $3.5 \mathrm{mM}$ extracellular $\mathrm{K}^{+}$was voltage-clamped to a holding potential of $-60 \mathrm{mV}$ and stepped to $-35 \mathrm{mV}$ for $900 \mathrm{~ms}$. The decay of the tail current that followed this step depolarization was then examined upon returning to a series of holding potentials between -59 and $-101 \mathrm{mV}$. In Fig. 2C, we have plotted the peak amplitudes of the $I_{\text {Fast }}$ and $I_{\text {Slow }}$ components of the tail current as a function of the membrane potential to which the cell was clamped upon termination of the depolarizing step. As this figure shows, the 2 components of the tail current reversed at different membrane potentials, $-63 \mathrm{mV}$ for the $I_{\text {Fast }}$ component (filled circles) and $-88 \mathrm{mV}$ for the $I_{\text {Slow }}$ component (open circles). Overall, the mean reversal potentials for $I_{\text {Fast }}$ and $I_{\text {Slow }}$ were $-74.5 \pm 2.4 \mathrm{mV}(n=8)$ and $-95.5 \pm 2.6(n=4)$, respectively, when determined in normal ACSF containing $3.5 \mathrm{mM}$ extracellular $\mathrm{K}^{+}$. The reversal potential determined for $I_{\text {Slow }}$ agreed well with a theoretical calculation of $-97 \mathrm{mV}$ for the potassium equilibrium potential $\left(E_{\mathrm{K}}\right)$, assuming an internal $\mathrm{K}^{+}$ concentration in BLA neurons of $165 \mathrm{mM}$, a value derived from measurements of $E_{\mathrm{K}}$ in hippocampal pyramidal neurons ${ }^{2}$.

In the experiment shown in Fig. 2, perfusion of the slice with medium containing high external $\mathrm{K}^{+}(15$ $\mathrm{mM}$ ) shifted the reversal potentials for both $I_{\text {Fast }}$ and $I_{\text {Slow }}$ in the depolarizing direction. Under these conditions, measurements of tail current decay made upon
A

$$
3.5 \mathrm{mM} \mathrm{K}^{+}
$$

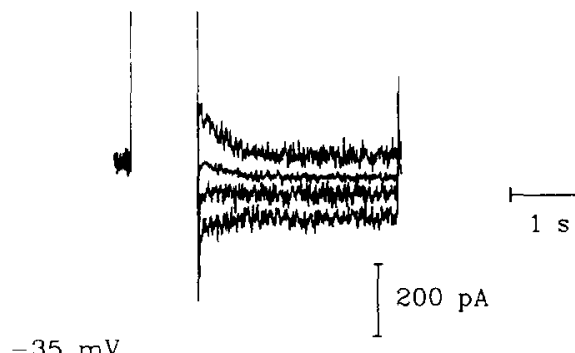

$\mathrm{B}$

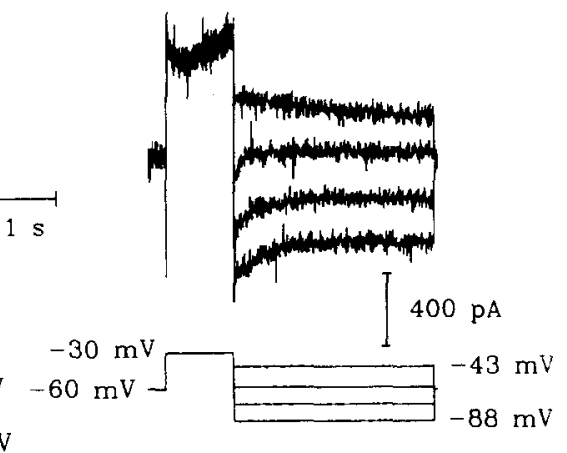

$\mathrm{C}$

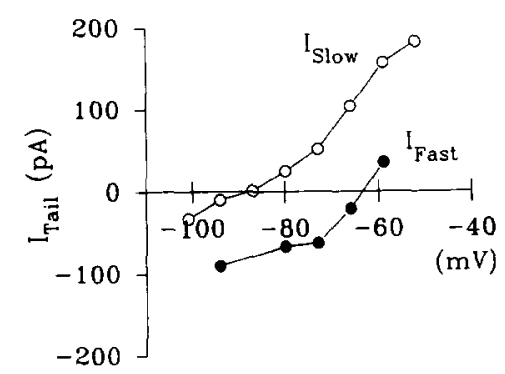

$\mathrm{D}$

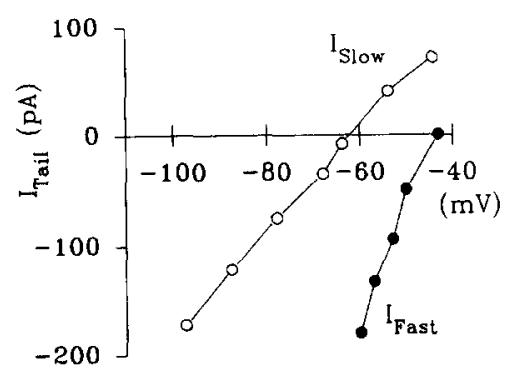

Fig. 2. Determination of the reversal potentials for $I_{\text {Fast }}$ and $I_{\text {Slow }}$ during perfusion of ACSF containing normal and elevated levels of potassium. For these experiments, $1 \mu \mathrm{M}$ TTX was included in all bathing media, along with $1 \mathrm{mM} \mathrm{Cs}^{+}$to block the hyperpolarization-activated $\mathrm{H}$-current. A: voltage-clamp records from a pyramidal neuron in normal $\left(3.5 \mathrm{mM} \mathrm{K}^{+}\right)$ACSF. Tail currents were evoked by a $900 \mathrm{~ms}$ depolarizing voltage step to $-35 \mathrm{mV}$ from a holding potential of $-60 \mathrm{mV}$ and examined upon returning to different holding potentials between -59 and $-101 \mathrm{mV}$. Resting potential of the cell was $-65 \mathrm{mV}$. B: tail currents recorded at holding potentials between -43 and $-88 \mathrm{mV}$ from the same cell after switching the bathing medium to ACSF containing $15 \mathrm{mM} \mathrm{K}^{+}$. The resting potential was $-48 \mathrm{mV}$. C,D: plots of peak amplitudes of the isolated fast and slow tail current components $\left(I_{\text {Tail }}\right)$, determined from individual single exponential curve fits, as a function of holding potential after the depolarizing step. The reversal potential for each component was estimated from the zero current level. The reversal potential of $I_{\text {Fast }}(\bullet)$ was shifted from $-63 \mathrm{mV}$ in normal ACSF to $-43 \mathrm{mV}$ in ACSF containing elevated $\mathrm{K}^{+}$. The reversal potential for $I_{\text {Slow }}(0)$ was shifted from -88 $\mathrm{mV}$ to $-58 \mathrm{mV}$ by the same 4.3 -fold increase in extracellular $\mathrm{K}^{+}$concentration. 
returning to holding potentials between -88 and -43 $\mathrm{mV}$ (Fig. 2B) yielded reversal potentials of -43 for $I_{\text {Fast }}$ and $-58 \mathrm{mV}$ for the $I_{\text {Slow }}$ component (Fig. 2D). Measurements obtained from 5 pyramidal neurons exposed to $15 \mathrm{mM} \mathrm{K}^{+}$ACSF yielded a mean reversal potential for $I_{\text {Fast }}$ of $-55.6 \pm 4.0 \mathrm{mV}$, while that for $I_{\text {Slow }}$ was $-59.0 \pm 2.6 \mathrm{mV}$. The $37 \mathrm{mV}$ positive shift in the reversal potential of $I_{\text {Slow }}$, from -96 to $-59 \mathrm{mV}$, produced by an increase in extracellular $\mathrm{K}^{+}$concentration from 3.5 to $15 \mathrm{mM} \mathrm{K}^{+}$is exactly that predicted by the Nernst equation, and indicates that the $I_{\text {Slow }}$ component of the tail current was a pure $\mathrm{K}^{+}$conductance. On the other hand, the finding that the same 4.3-fold increase in external $\mathrm{K}^{+}$concentration yielded only a 19 $\mathrm{mV}$ positive shift in the reversal potential of $I_{\text {Fast }}$ indicates that this portion of the tail current was substantially, but not exclusively, a $\mathrm{K}^{+}$conductance.

During this series of experiments, we also examined the effect that changes in the holding potential had on the decay rates of the fast and slow components of the AHP tail current. These experiments were carried out in normal ACSF containing $3.5 \mathrm{mM} \mathrm{K}^{+}$. In 5 pyramidal neurons, the rate of decay for $I_{\text {Slow }}$ was unaffected by changes in holding potential over the range of -50 to $-70 \mathrm{mV}$. The effect of varying membrane potential on the $I_{\text {Fast }}$ rate of decay was less clear. In 3 neurons, the rate appeared to accelerate with hyperpolarization, but this was not observed in the other 2 neurons.

\section{$\mathrm{Ca}^{2+}$-dependence of $I_{\text {Fast }}$ and $I_{\text {Slow }}$}

Results from an earlier current-clamp study of BLA pyramidal neurons suggested that $\mathrm{Ca}^{2+}$-activated $\mathrm{K}^{+}$ currents may be involved in the accommodation response and production of the medium and slow AHP in these cells. Thus, addition of $\mathrm{Cd}^{2+}$ to the bathing medium or inclusion of EGTA in the recording electrode reduced the amplitude of the current-evoked mAHP and eliminated both accommodation and the sAHP ${ }^{29}$. The involvement of $\mathrm{Ca}^{2+}$-sensitive outward currents in the production of the AHP was confirmed in voltage-clamped BLA neurons. Fig. 3 shows the results of an experiment in which we examined the sensitivity of AHP tail currents elicited by depolarizing voltage steps to changes in external $\mathrm{Ca}^{2+}$ concentration. Switching the bathing solution from normal ACSF containing $3 \mathrm{mM} \mathrm{Ca}^{2+}$ to ACSF in which $\mathrm{Ca}^{2+}$ was replaced with $10 \mathrm{mM} \mathrm{Mg}^{2+}$ virtually eliminated the $I_{\text {Slow }}$ portion of the tail current, reducing it from 441 to $28 \mathrm{pA}$. At the same time, the peak amplitude of the $I_{\text {Fast }}$ component was also reduced, from 417 to $189 \mathrm{pA}$. In addition, perfusion of $0-\mathrm{Ca}^{2+}$ ACSF substantially reduced the amplitude of the peak outward current recorded during the depolarizing voltage step. Current

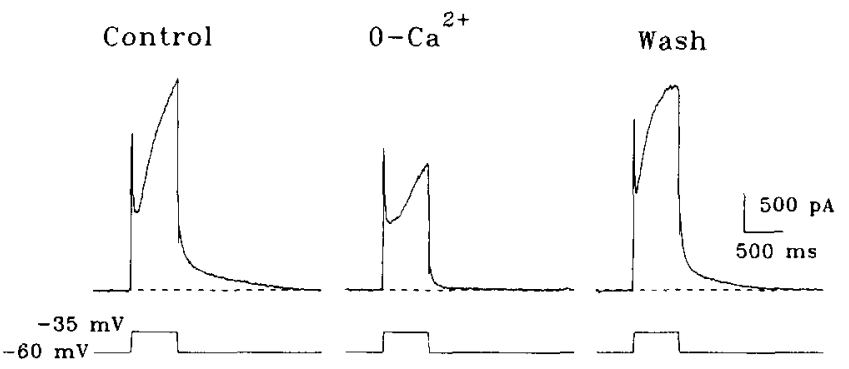

Fig. 3. Dependence of depolarization-evoked outward currents on the presence of extracellular calcium. In this pyramidal neuron, a 500 $\mathrm{ms}$ depolarizing step to $-35 \mathrm{mV}$ from a holding potential of $-60 \mathrm{mV}$ elicited a large outward current during the step, followed by a biphasic tail current. Repetition of the voltage step protocol $15 \mathrm{~min}$ after changing from normal bathing medium to ACSF containing $0-\mathrm{Ca}^{2+}$ revealed large reductions in the $I_{\text {Fast }}$ and $I_{\text {Slow }}$ components of the tail current, as well as in the amplitude of the outward current generated during the voltage step. These changes were reversed after washing with normal ACSF for $15 \mathrm{~min}$. TTX $(1 \mu \mathrm{M})$ was included in all bathing media. Each trace is an average of 3 successive sweeps.

amplitudes returned to control levels upon washing with normal ACSF. Loss of $I_{\text {Slow }}$ and reductions in $I_{\text {Fast }}$ amplitude were seen in all experiments with BLA neurons exposed to $0-\mathrm{Ca}^{2+} \mathrm{ACSF}(n=2)$, or to normal ACSF containing the $\mathrm{Ca}^{2+}$ channel blockers $\mathrm{Cd}^{2+}(200$ $\mu \mathrm{M}, n=2)$ or $\mathrm{Co}^{2+}(2 \mathrm{mM}, n=2)$. Overall, treatments designed to reduce or block $\mathrm{Ca}^{2+}$ influx produced a $84.8 \pm 6.1 \%(n=6)$ reduction in the $I_{\text {Slow }}$ component of the AHP tail current and a $63.5 \pm 5.7 \%(n=6)$ reduction in the $I_{\text {Fast }}$ component. These findings suggest that $I_{\text {Slow }}$ resulted from the action of a slowly decaying $\mathrm{Ca}^{2+}$-dependent conductance, while a more rapidly decaying $\mathrm{Ca}^{2+}$-sensitive outward conductance contributed in part to production of $I_{\text {Fast }}$.

\section{Characterization of $I_{\text {Slow }}$}

The data presented above indicate that the $I_{\text {Slow }}$ portion of the AHP tail current was produced by a slowly decaying, $\mathrm{Ca}^{2+}$-activated $\mathrm{K}^{+}$current. A current with these characteristics, termed $I_{\mathrm{AHP}}$, has been shown to be responsible for production of the SAHP in several neuronal cell types, including bullfrog sympathetic neurons $^{24,28}$, hippocampal pyramidal neurons ${ }^{17,19}$, sensorimotor cortical neurons ${ }^{25}$ and olfactory cortical neurons ${ }^{11}$. Intracellular injection of cyclic-AMP or bath application of its membrane permeate analogues has been shown to block $I_{\mathrm{AHP}}$ and the sAHP in hippocampal neurons ${ }^{18,19}$. These treatments also block accommodation and the SAHP in BLA pyramidal neurons ${ }^{29}$, suggesting the presence of a current similar to $I_{\mathrm{AHP}}$ in BLA neurons. To test the ability of intracellular administration of cyclic-AMP to block the $I_{\text {Slow }}$ component of AHP tail currents recorded in BLA pyramidal neurons, we impaled neurons with recording electrodes containing $100 \mathrm{mM}$ cyclic-AMP. Within a few minutes after 


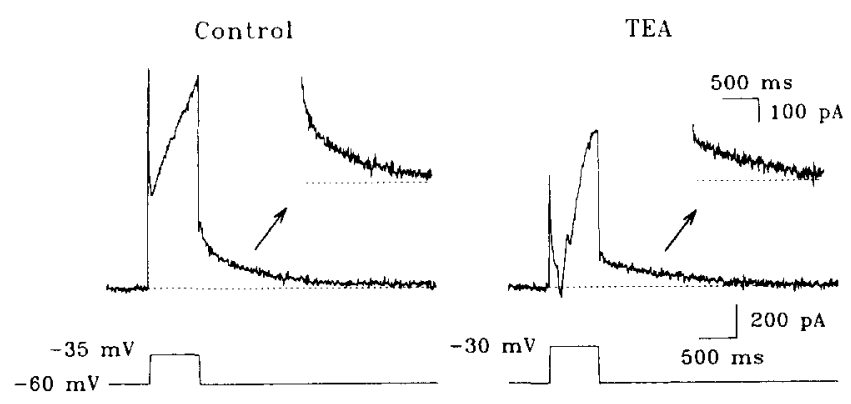

Fig. 4. Inhibition of the $I_{\text {Fast }}$ portion of the tail current by TEA. Current responses were evoked by $900 \mathrm{~ms}$ depolarizing steps from a holding potential of $-60 \mathrm{mV}$ to the indicated command potentials. Superfusion of TEA $(5 \mathrm{mM})$ selectively inhibited the $I_{\text {Fast }}$ component of the tail current, reducing its peak amplitude from 196 to 40 pA. The $I_{\text {Siow }}$ tail current component was uneffected. The initial portions of the tail currents are shown at a higher gain in the inserts. Records are averages of 3 sweeps each.

the initial impalement, the accommodation response, the sAHP and $I_{\text {Slow }}$ were all largely eliminated $(n=4)$. In comparison, the mAHP and $I_{\text {Fast }}$ were unaffected by intracellular iontophoresis of the nucleotide. These data support the hypothesis that the slowly decaying portion of AHP tail currents recorded in BLA pyramidal neurons was produced by $I_{\mathrm{AHP}}$, and suggests that this current contributes to production of the accommodation response and the SAHP. Interestingly, the beevenom toxin, apamin (50-500 $\mathrm{nM}$ ), a selective blocker of $I_{\mathrm{AHP}}$ in bullfrog ganglion cells ${ }^{24}$ and rat supraoptic neurons ${ }^{4}$, did not effect either the fast or slow portions of AHP tail currents recorded in BLA pyramidal neurons $(n=4)$. It should be noted, however, that apamin does not block $I_{\mathrm{AHP}}$ in hippocampal pyramidal neurons $^{27}$ or olfactory cortical neurons ${ }^{11}$ and thus is not a definitive test for this current.
Characterization of the conductances underlying $I_{\text {Fast }}$ Our findings indicate that a substantial portion of the $I_{\text {Fast }}$ component of the AHP tail current was $\mathrm{Ca}^{2+}$ sensitive, suggesting the involvement of a rapidly decaying $\mathrm{Ca}^{2+}$-activated $\mathrm{K}^{+}$current. A current of this type, termed $I_{C}$, has been shown to be involved in the production of the mAHP in bullfrog sympathetic neurons $^{24}$, hippocampal pyramidal neurons $\mathrm{s}^{6,27,30}$ and cortical pyramidal neurons ${ }^{25}$. In these cell types, $I_{\mathrm{C}}$ is inhibited by $\mathrm{TEA}^{1,6,27}$. We have previously shown that TEA (0.2-1 mM) selectively reduces the current-evoked mAHP while sparing the SAHP in BLA pyramidal neurons ${ }^{29}$, suggesting a possible involvement of $I_{\mathrm{C}}$ in the production of the mAHP. Thus, we examined the TEA sensitivity of the $I_{\text {Fast }}$ portion of AHP tail currents recorded in BLA pyramidal neurons. As illustrated in Fig. 4, TEA ( $5 \mathrm{mM})$ selectively blocked the $I_{\text {Fast }}$ portion of the tail current, reducing its peak amplitude in this case from 196 to $40 \mathrm{pA}$, with little or no effect on the $I_{\text {Slow }}$ component. Overall, lower concentrations of TEA $(1-2 \mathrm{mM})$ reduced $I_{\text {Fast }}$ by $55 \pm 5 \%$ $(n=3)$, while $5 \mathrm{mM}$ TEA largely eliminated this portion of the tail current, reducing it by an average of $93 \pm 6 \%(n=3)$. These findings are consistent with the possible contribution of $I_{\mathrm{C}}$ to the rapidly decaying portion of the AHP tail current.

Inhibition of $I_{\text {Fast }}$ by TEA is not a definitive test for $I_{C}$, however. The mAHP in hippocampal and olfactory cortical neurons is also produced in part by the M-current $\left(I_{\mathrm{M}}\right)^{11,27,30}$, a voltage- and muscarinic-sensitive current $^{5,13}$ that is inhibited by similar concentrations of TEA $^{11,27}$. This current is also present in BLA pyramidal neurons ${ }^{32}$. We have found that the amplitude of $I_{\mathrm{M}}$ in BLA neurons, measured during a $1 \mathrm{~s}$ hyperpolariz-
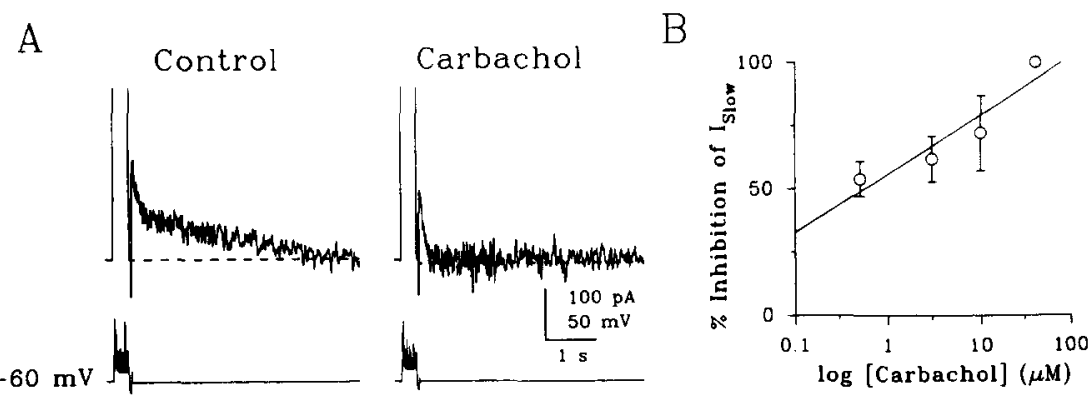

Fig. 5. Inhibition of the $I_{\text {Slow }}$ component of the AHP tail current by carbachol. A: an unclamped BLA neuron was maintained at a resting potential level of $-60 \mathrm{mV}$ with steady DC current injection. In the absence of TTX, a $500 \mathrm{~ms}$ depolarizing current pulse elicited a burst of action potentials (lower records). Switching to voltage-clamp mode at a holding potential of $-60 \mathrm{mV}$ upon termination of the current pulse (hybrid-clamp) revealed a biphasic tail current underlying the AHP (control, upper record). Addition of carbachol (10 $\mu \mathrm{M})$ to the perfusate eliminated the $I_{\text {Slow }}$ portion of the tail current and produced a small reduction in the peak amplitude of the $I_{\text {Fast }}$ component, from 133 to 112 pA. Dashed lines indicate baseline current levels at the $-60 \mathrm{mV}$ holding potential. Each trace represents the average of 4 sweeps. B: concentration-response relationship for the inhibition of $I_{\text {Slow }}$ by carbachol, determined from a total of 21 neurons. The percent reduction in $I_{\text {Slow }}$ peak amplitude, measured at a holding potential of $-60 \mathrm{mV}$, is plotted against the log concentration of carbachol. The fitted line yielded an approximate $\mathrm{IC}_{50}$ of $0.5 \mu \mathrm{M}$. Each point represents the mean of measurements from 4-7 pyramidal neurons. At the highest concentration of agonist tested $(40 \mu \mathrm{M}), I_{\text {Slow }}$ was completely inhibited in all cases and thus the size of the point obscures the error bar. 
ing voltage step to $-55 \mathrm{mV}$ from a holding potential of $-40 \mathrm{mV}$, was reduced by an average of $59 \%(n=2)$ during perfusion of $1 \mathrm{mM} \mathrm{TEA}$ and $86 \%(n=2)$ by 5 mM TEA (Womble and Moises, unpublished observations), indicating that this current could also contribute to the TEA-sensitivity of $I_{\text {Fast }}$. Therefore, to test for the possible involvement of $I_{\mathrm{M}}$ in the production of $I_{\text {Fast }}$, we examined this portion of the AHP tail current during perfusion of carbachol, a cholinergic agonist that is a potent inhibitor of $I_{\mathrm{M}}^{13,19,32}$ but not of $I_{\mathrm{C}}^{6,18}$. As illustrated by the hybrid-clamp experiment in Fig. 5A, perfusion of $10 \mu \mathrm{M}$ carbachol resulted in a small decrease in $I_{\text {Fast }}$ amplitude, in this case reducing it from 133 to $112 \mathrm{pA}$. Overall, administration of 10 40 $\mu \mathrm{M}$ carbachol, concentrations which have previously been found to largely eliminate $I_{\mathrm{M}}$ in BLA neurons ${ }^{32}$, reduced the $I_{\text {Fast }}$ portion of the AHP tail current by $29 \pm 9 \%(n=7)$. In two other neurons impaled with cyclic-AMP-containing electrodes to block the $I_{\text {Slow }}$ portion of the tail current, application of carbachol reduced $I_{\text {Fast }}$ by an average of $44 \%$, indicating that the observed reduction in $I_{\text {Fast }}$ was not due to inhibition of $I_{\text {Slow }}$. These findings suggests that $I_{\mathrm{M}}$ contributes a small but significant portion to the $I_{\text {Fast }}$ component of the AHP tail current.

\section{Muscarinic modulation of $I_{\text {Slow }}$}

Muscarinic receptor activation results in inhibition of the sAHP and its underlying $I_{\mathrm{AHP}}$ in several neuronal cell types, including frog sympathetic neurons ${ }^{24}$, olfactory cortical neurons ${ }^{11}$, sensorimotor cortical neurons $^{25}$ and hippocampal pyramidal neurons ${ }^{3,9,10,18,19}$. Similarly, we have previously reported that application of muscarinic agonists reduces the accommodation response and inhibits the SAHP in BLA pyramidal neurons $^{29}$. Therefore we sought to determine the muscarinic sensitivity of the $I_{\text {Slow }}$ portion of AHP tail currents recorded in BLA neurons. As illustrated in Fig. 5A, application of carbachol $(10 \mu \mathrm{M})$ selectively inhibited the $I_{\text {Slow }}$ portion of the AHP tail current. In other experiments, when $I_{\text {Slow }}$ was not completely blocked, it could be seen that the rate of decay for the residual $I_{\text {Slow }}$ component was unchanged. The inhibitory effect of carbachol on $I_{\text {Slow }}$ could be reversed by washing with ACSF containing $1 \mu \mathrm{M}$ atropine (not shown), suggesting that this effect was mediated by muscarinic receptor activation. The concentration-response relationship for the inhibition of $I_{\text {Slow }}$ by carbachol was determined in 21 BLA pyramidal neurons using agonist concentrations of $0.5-40 \mu \mathrm{M}$ (Fig. 5B). The inhibitory effect of carbachol was dose-dependent, with an $\mathrm{IC}_{50}$ of approximately $0.5 \mu \mathrm{M}$, similar to that obtained for inhibition of the SAHP in BLA pyramidal neurons ${ }^{29}$ and $I_{\mathrm{AHP}}$ in hippocampal pyramidal neurons $^{19}$.

\section{Effects of synaptic stimulation}

The BLA receives an extensive cholinergic innervation from the nucleus basalis and adjacent regions of the ventral forebrain ${ }^{8,14}$. Cholinergic afferents arise in the substantia innominata (SI) portion of this region and course through the external capsule (EC) on their way to innervate the $\mathrm{BLA}^{15,23}$. We have previously shown that activation of these afferents by direct electrical stimulation of the SI or EC in slices of the ventral forebrain produces inhibitions of both accommodation and the sAHP, effects which were prevented in the presence of atropine, indicating mediation by muscarinic receptors ${ }^{29}$. Therefore, we sought to determine whether stimulation of this afferent pathway would mimic the inhibitory effects of carbachol on the slow component of the AHP tail current recorded in BLA neurons. For these experiments, the tail current was examined before and several seconds after tetanic activation of amygdalopetal afferents $(30 \mathrm{~Hz}$ repetitive stimulation for $500 \mathrm{~ms}$ with $0.2 \mathrm{~ms}$ stimuli). We found that afferent pathway stimulation produced an average reduction in $I_{\text {Slow }}$ amplitude of $28 \pm 8 \%(n=4)$. Stimulations applied in the presence of the anticholinesterase agent eserine $(5 \mu \mathrm{M})$ increased the magnitude of $I_{\text {Slow }}$ inhibition to $51 \pm 16 \%(n=5)$. Fig. 6 illustrates the largest change in $I_{\text {Slow }}$ amplitude that we observed following afferent stimulation. The perfusing medium for this experiment contained $5 \mu \mathrm{M}$ eserine, and $20 \mu \mathrm{M}$ picrotoxin to block the fast inhibitory

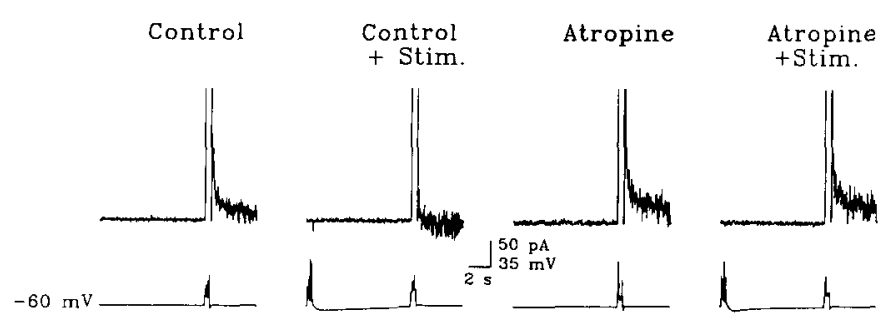

Fig. 6. Hybrid-clamp records obtained in the absence of TTX, showing inhibition of the AHP tail current following stimulation of the cholinergic afferent pathway to the BLA. The unclamped neuron was held at a membrane potential of $-60 \mathrm{mV}$ with steady $\mathrm{DC}$ current prior to application of a $500 \mathrm{~ms}$ depolarizing current pulse to elicit a burst of action potentials (lower traces). Upon termination of the current pulse, a rapid switch to voltage-clamp mode at a holding potential of $-60 \mathrm{mV}$ revealed the biphasic AHP tail current (Control, upper record). Tail current amplitude was greatly reduced following tetanic stimulation ( $30 \mathrm{~Hz}$ for $500 \mathrm{~ms}$ with $0.2 \mathrm{~ms}$ stimuli) of the external capsule pathway to the BLA (Control + Stimulation). After recovery of the tail current and addition of atropine $(1 \mu \mathrm{M})$ to the perfusing medium, a tail current was again elicited (Atropine). Afferent stimulation in the presence of atropine failed to reduce tail current amplitude (Atropine + Stimulation). Eserine $(5 \mu \mathrm{M})$ and picrotoxin $(20 \mu \mathrm{M})$ were included in all bathing media. 
post-synaptic potential normally evoked by synaptic stimulation $^{29}$. A biphașic AHP tail current was evoked at a holding potential of $-60 \mathrm{mV}$ using the hybridclamp technique. Afferent activation reduced the peak amplitude of the $I_{\text {Slow }}$ component in this cell from 42 $\mathrm{pA}$ to $2 \mathrm{pA}$. At the same time, the $I_{\text {Fast }}$ portion of the tail current was also reduced, from 80 to $25 \mathrm{pA}$. Similar stimulations applied to the unclamped neuron were accompanied by reductions in spike frequency accommodation and the sAHP (not shown). The perfusing saline was then switched to ACSF containing $1 \mu \mathrm{M}$ atropine, in addition to eserine and picrotoxin. Afferent stimulation under these conditions failed to produce a reduction in tail current amplitude, an action of atropine that was also observed in 2 other neurons. These findings confirm that activation of the cholinergic afferent pathway running from the ventral forebrain region to the BLA inhibits $I_{\text {Slow }}$ and results in reductions of both spike frequency accommodation and the sAHP, suggesting that activation of this pathway in vivo may have a significant impact on the functioning of BLA pyramidal neurons.

\section{DISCUSSION}

Pyramidal neurons of the BLA exhibit a characteristic biphasic AHP following a current-evoked burst of action potentials. The AHP can be divided into an initial short-lived medium AHP, that may last up to 100-200 ms, followed by a long-lasting slow AHP that decays over a period of several seconds. Voltage-clamp analysis showed that depolarization of BLA neurons was followed by a prolonged outward tail current. This tail current was responsible for generation of the AHP and could be divided into 2 current components on the basis of their different rates of decay. The initial portion of the AHP tail current, termed $I_{\text {Fast }}$, decayed rapidly and corresponded in duration to the mAHP, while the $I_{\text {Slow }}$ component of the tail current decayed much more slowly and was responsible for production of the SAHP.

The $I_{\text {Slow }}$ portion of the AHP tail current appeared to reflect the exponential decay of a single, slowly decaying $\mathrm{Ca}^{2+}$-activated $\mathrm{K}^{+}$current. Thus, $I_{\text {Slow }}$ was highly sensitive to treatments which caused reductions in voltage-gated $\mathrm{Ca}^{2+}$ influx and was a pure $\mathrm{K}^{+}$conductance, as evidenced by having a reversal potential close to $E_{\mathrm{K}}$. It was not blocked by apamin or low concentrations of TEA and showed no voltage sensitivity in its rate of decay. However, $I_{\text {Stow }}$ was markedly reduced during intracellular loading of the cell with cyclic-AMP and was inhibited by carbachol in a dosedependent and atropine-sensitive manner. Therefore we conclude that the $I_{\text {Siow }}$ component of the AHP tail current recorded in BLA pyramidal neurons is similar to the slowly decaying $\mathrm{Ca}^{2+}$-activated $\mathrm{K}^{+}$conductance, termed $I_{\mathrm{AHP}}$, previously described in other neuronal cell types, including bullfrog sympathetic neurons ${ }^{24,28}$, hippocampal pyramidal neurons ${ }^{17,19}$, sensorimotor cortical neurons ${ }^{25}$ and olfactory cortex neurons ${ }^{11}$.

Since we found that reductions in $\mathrm{Ca}^{2+}$ influx during the depolarizing voltage step greatly decreased the amplitude of the ensuing slow portion of the AHP tail current, this raised the possibility that the carbacholinduced inhibition of $I_{\text {Slow }}$ was secondary to inhibition of the voltage-dependent $\mathrm{Ca}^{2+}$ current. Indeed, muscarinic receptor activation has been shown to block the $\mathrm{Ca}^{2+}$ current of pyramidal neurons in cultured hippocampal slices ${ }^{12}$. The finding that the carbachol-induced reductions in the amplitude of $I_{\text {Slow }}$ were not associated with changes in the decay rate of this current component, however, suggested that decreases in the underlying $I_{\mathrm{AHP}}$ conductance did not result from reductions in $\mathrm{Ca}^{2+}$ influx. This conclusion is supported by our previous current-clamp study which demonstrated that the amplitude and duration of $\mathrm{Ca}^{2+}$ spikes elicited by BLA neuron depolarization in the presence of TTX and TEA were uneffected by carbachol ${ }^{29}$. A similar conclusion was also reached by Knopfel et al. ${ }^{16}$ who used intracellular recording techniques combined with microfluorometric measurements of intracellular $\mathrm{Ca}^{2+}$ levels in hippocampal pyramidal neurons to show that muscarinic inhibition of $I_{\mathrm{AHP}}$ occurs without a corresponding reduction in internal $\mathrm{Ca}^{2+}$ levels.

Previous work with BLA pyramidal neurons has shown that accommodation in the frequency of action potential firing during a prolonged depolarizing current pulse was reduced by treatments which also produced a concurrent reduction in the sAHP, including superfusion of medium containing $\mathrm{Cd}^{2+}$ or carbachol, elevated intracellular cyclic-AMP concentrations, or activation of cholinergic afferent fibers, leading to the suggestion that accommodation and the SAHP were produced by the action of the same current ${ }^{29}$. In the present study, voltage-clamp recordings demonstrated that these types of treatments all specifically inhibited the $I_{\text {Slow }}$ portion of the AHP tail current. These findings indicate that $I_{\mathrm{AHP}}$ is largely responsible for production of both the accommodation response and the SAHP in BLA pyramidal neurons, in agreement with similar findings from frog sympathetic neurons ${ }^{24}$, hippocampal pyramidal neurons ${ }^{17,18}$ and olfactory cortical neurons ${ }^{\prime \prime}$.

In contrast to the slowly decaying portion of the AHP tail current, the $I_{\text {Fast }}$ component appeared to consist of more than a single current. Part of $I_{\text {Fast }}$ was 
due to the action of a rapidly decaying $\mathrm{Ca}^{2+}$-dependent outward conductance, since the peak amplitude of this component was consistently diminished by treatments which reduced or abolished voltage-dependent $\mathrm{Ca}^{2+}$ influx during the preceding depolarization. The $I_{\text {Fast }}$ component was predominantly a $\mathrm{K}^{+}$conductance, as evidenced by its reversal potential of $-75 \mathrm{mV}$ when measured from an initial holding potential of $-60 \mathrm{mV}$, a value that agrees with the reversal potential obtained for the mAHP in hippocampal pyramidal neurons ${ }^{30}$. A similar reversal potential has been obtained in hippocampal neurons for the rapidly decaying, $\mathrm{Ca}^{2+}$. activated $\mathrm{K}^{+}$current, $I_{\mathrm{C}}$, which partially underlies production of the mAHP in these cells ${ }^{6,30}$. These findings suggest that a portion of the $I_{\text {Fast }}$ component of the AHP tail current recorded in BLA neurons might be attributable to a rapidly decaying $\mathrm{Ca}^{2+}$-activated $\mathrm{K}^{+}$ current similar to the $I_{\mathrm{C}}$ of bullfrog sympathetic neurons $^{1,24}$ and hippocampal pyramidal neurons ${ }^{6,17,18}$.

A second, carbachol-sensitive current appeared to also contribute to the $I_{\text {Fast }}$ portion of the AHP tail current. Since $I_{\mathrm{C}}$ is not inhibited by carbachol ${ }^{6,18}$, the portion of $I_{\text {Fast }}$ which was blocked by this agonist may be due to inhibition of the muscarinic-sensitive M-current $^{5,13,19}$. Studies have demonstrated that $I_{\mathrm{M}}$ contributes to production of the mAHP in hippocampal pyramidal neurons ${ }^{27,30}$ and olfactory cortical neurons ${ }^{11}$. We have previously shown that this current is also present in BLA pyramidal neurons ${ }^{32}$, where it has many characteristics that make it a likely contributor to the $I_{\text {Fast }}$ component of the AHP tail current. Thus, $I_{\mathrm{M}}$ is a $\mathrm{K}^{+}$conductance activated by membrane depolarization, with a decay tau of approximately $150 \mathrm{~ms}$ at a holding potential of $-60 \mathrm{mV}^{32}$, characteristics that were also associated with the $I_{\text {Fast }}$ portion of the AHP tail current. The involvement of both $I_{\mathrm{M}}$ and $I_{\mathrm{C}}$ in the production of $I_{\text {Fast }}$ is consistent with the finding that this portion of the AHP tail current was largely eliminated by $5 \mathrm{mM}$ TEA, a drug concentration that inhibits both $I_{\mathrm{M}}^{11,27}$ and $I_{\mathrm{C}}^{1,6,27}$. This conclusion is also supported by the finding that cholinergic afferent pathway stimulation in the presence of eserine resulted in a reduction of the $I_{\text {Fast }}$ tail current component, an action that was prevented by atropine.

The present experiments were performed at a holding potential of $-60 \mathrm{mV}$ to prevent contamination of the AHP tail current by the H-current $\left(I_{\mathrm{H}}\right)$, a mixed cationic inward current activated by hyperpolarization $^{13,22,26}$. In separate experiments, we have found that $2 \mathrm{mM}$ extracellular $\mathrm{Cs}^{+}$inhibited $I_{\mathrm{H}}$ in BLA neurons and reduced the amplitude of the MAHP when the preceding burst of action potentials was evoked from the normal resting potential level of $-70 \mathrm{mV}$ (Womble and Moises, unpublished observations). This finding suggests that $I_{\mathrm{H}}$ also contributes to production of the mAHP normally observed in unclamped BLA neurons. Thus, the data we have obtained suggests that several currents contribute to the mAHP in BLA pyramidal neurons, indicating that these cells are similar to hippocampal pyramidal neurons, in which a mixture $I_{\mathrm{C}}{ }^{\prime}$, $I_{\mathrm{M}}$ and $I_{\mathrm{H}}$ all contribute to generation of the $\mathrm{mAHP}{ }^{27,30}$.

We have previously shown that stimulation of afferent pathways from the ventral forebrain region to the BLA reduces both accommodation and the slow $\mathrm{AHP}^{29}$. These actions were prevented in the presence of TTX or atropine, suggesting they were mediated by synaptic release of acetylcholine acting on muscarinic receptors ${ }^{29}$. In the present study, similar stimulations inhibited the $I_{\text {Slow }}$ portion of the AHP tail current, an effect that was enhanced by eserine and prevented by atropine. These findings confirm the cholinergic nature of this afferent pathway. Our results suggest that the loss of $I_{\text {Slow }}$ produced following the activation of cholinergic fibers in vivo may have a significant impact on the size and duration of the AHP and on the rate of action potential firing in BLA pyramidal neurons.

Stimulation of forebrain cholinergic inputs to the BLA or application of muscarinic agonists to neurons in the in vitro slice preparation induces several changes in unclamped BLA pyramidal cells, including a slow membrane depolarization associated with an increase in input resistance and blockade of the slow AHP and accommodation response ${ }^{29}$. The net effect of these cholinergic actions is to greatly increase the responsiveness of BLA neurons to subsequent excitatory stimuli. The increased input resistance and membrane depolarization have previously been shown to be produced by the muscarinic inhibitions of the M-current and a voltage-insensitive $\mathrm{K}^{+}$leak conductance $\left(I_{\text {Leak }}\right)^{32}$. In the present study, we have demonstrated that the losses of accommodation and the SAHP are due to the muscarinic inhibition of the $I_{\text {Slow }}$ component of the AHP tail current. This current component is more sensitive to the inhibitory actions of carbachol $\left(\mathrm{IC}_{50}=0.5 \mu \mathrm{M}\right)$ than are either $I_{\mathrm{M}}$ or $I_{\text {Leak }}$ (each with $\left.\mathrm{IC}_{50}=2 \mu \mathrm{M}\right)^{32}$, suggesting that inhibition of $I_{\text {Slow }}$ and the accompanying reductions in accommodation and the slow AHP may represent the major actions of synaptically released acetylcholine. Thus, inhibition of $I_{\mathrm{AHP}}$ may be the most important factor in the cholinergic regulation of BLA neuronal excitability.

Acknowledgements. This work was supported by PHS Grants AG10667 and DA03365 to H.C.M. 


\section{REFERENCES}

1 Adams, P.R., Constanti, A, Brown, D.A. and Clark, R.B., Intracellular $\mathrm{Ca}^{2+}$ activates a fast voltage-sensitive $\mathrm{K}^{+}$current in vertebrate sympathetic neurons, Nature, 296 (1982) 746-749.

2 Benson, D.M., Blitzer, R.D. and Landau, E.M., An analysis of the depolarization produced in guinea-pig hippocampus by cholinergic receptor stimulation, J. Physiol., 404 (1988) 479-496.

3 Benardo, L.S. and Prince, D.A., Cholinergic excitation of mammalian hippocampal pyramidal cells, Brain Res., 249 (1982) 315331.

4 Bourque, C.W. and Brown, D.A., Apamin and d-tubocurarine block the afterhyperpolarization of rat supraoptic neurosecretory neurons, Neurosci. Lett., 82 (1987) 185-190.

5 Brown, D.A. and Adams, P.R., Muscarinic suppression of a novel voltage-sensitive $\mathrm{K}^{+}$current in a vertebrate neurone, Nature, 283 (1980) 673-676.

6 Brown, D.A. and Griffith, W.H., Calcium-activated outward current in voltage-clamped hippocampal neurones of the guinea-pig, J. Physiol., 337 (1983) 287-301.

7 Carlsen, J. and Heimer, L., The basolateral amygdaloid complex as a cortical-like structure, Brain Res., 441 (1988) 377-380.

8 Carlsen, J., Zaborszky, L. and Heimer, L., Cholinergic projections from the basal forebrain to the basolateral amygdaloid complex: a combined retrograde fluorescent and immunohistochemical study, J. Comp. Neurol., 234 (1985) 155-167.

9 Cole, A.E. and Nicoll, R.A., Acetylcholine mediates a slow synaptic potential in hippocampal pyramidal cells, Science, 221 (1983) 1299-1301.

10 Cole, A.E. and Nicoll, R.A., Characterization of a slow cholinergic post-synaptic potential recorded in vitro from rat hippocampal pyramidal cells, J. Physiol., 352 (1984) 173-188.

11 Constanti, A. and Sim, J.A., Calcium-dependent potassium conductance in guinea-pig olfactory cortex neurones in vitro. $J$. Physiol., 387 (1987) 173-194.

12 Gähwiler, B.H. and Brown, D.A., Muscarinic affects calcium-currents in rat hippocampal pyramidal cell in vitro, Neurosci. Lett., 76 (1987) 301-306.

13 Halliwell, J.V. and Adams, P.R., Voltage-clamp analysis of muscarinic excitation in hippocampal neurons, Brain Res., 250 (1982) $71-92$.

14 Hellendall, R.P., Godfrey, D.A., Ross, C.D., Armstrong, D.M. and Price, J.L., The distribution of choline acetyltransferase in the rat amygdaloid complex and adjacent cortical areas, as determined by quantitative micro-assay and immunohistochemistry, $J$. Comp. Neurol., 249 (1986) 486-498.

15 Ichikawa, T. and Hirata, Y., Organization of choline acetyltransferase-containing structures in the forebrain of the rat, $J$. Neurosci., 6 (1986) 291-292.

16 Knopfel, T., Vranesic, I., Gähwiler, B.H., and Brown, D.A., Muscarinic and beta-adrenergic depression of the slow $\mathrm{Ca}^{2+}$. activated potassium conductance in hippocampal CA3 pyramidal cells is not mediated by a reduction of depolarization-induced cytosolic $\mathrm{Ca}^{2+}$ transients, Proc. Natl. Acad. Sci. USA, 87 (1990) $4083-4087$.

17 Lancaster, B. and Adams, P.R., Calcium-dependent current generating the afterhyperpolarization of hippocampal neurons, $J$. Neurophysiol., 55 (1986) 1268-1282.

18 Lancaster, B. and Nicoll, R.A., Properties of two calciumactivated hyperpolarizations in rat hippocampal neurones, $J$. Physiol., 389 (1987) 187-203.

19 Madison, D.V., Lancaster, B. and Nicoll, R.A., Voltage clamp analysis of cholinergic action in the hippocampus, J. Neurosci., 7 (1987) 733-741.

20 McDonald, A.J., Neurons of the lateral and basolateral amygdaloid nuclei: a Golgi study in the rat, J. Comp. Neurol., 212 (1982) 293-312.

21 McDonald, A.J., Neuronal organization of the lateral and basolateral amygdaloid nuclei in the rat, J. Comp. Neurol., 222 (1984) 589-606.

22 Moises, H.C. and Womble, M.D., Voltage-clamp analysis of potassium currents in basolateral amygdala neurons, Soc. Neurosci. Abstr., 16 (1990) 506.

23 Nagai, T., Kimura, H., Maeda, T., McGeer, P.L., Peng, F. and McGeer, E.G., Cholinergic projections from the basal forebrain to rat to the amygdala, $J$. Neurosci., 2 (1982) 513-520.

24 Pennefather, P., Lancaster, B., Adams, P.R. and Nicoll, R.A., Two distinct $\mathrm{Ca}$-dependent $\mathrm{K}$ currents in bullfrog sympathetic ganglion cells, Proc. Natl. Acad. Sci. USA, 82 (1985) 3040-3044.

25 Schwindt, P.C., Spain, W.J., Foehring, R.C., Chubb, M.C. and Crill, W.E., Slow conductances in neurons from cat sensorimotor cortex in vitro and their role in slow excitability changes, $J$. Neurophysiol., 59 (1988) 450-467.

26 Spain, W., Schwindt, P.C. and Crill, W.E., Anomalous rectification in neurons from cat sensorimotor cortex in vitro, J. Neurophysiol., 57 (1987) 1555-1576.

27 Storm, J.F., An after-hyperpolarization of medium duration in rat hippocampal pyramidal cells, J. Physiol., 409 (1989) 171-190.

28 Tanaka, K. and Kuba, K., The $\mathrm{Ca}^{2+}$-sensitive $\mathrm{K}^{+}$-currents underlying the slow afterhyperpolarization of bullfrog sympathetic neurons, Pflüg. Arch., 410 (1987) 234-242.

29 Washburn, M.S. and Moises, H.C., Muscarinic responses of rat basolateral amygdaloid neurones recorded in vitro, J. Physiol., 449 (1992) 121-154.

30 Williamson, A. and Alger, B.E., Characterization of an early afterhyperpolarization after a brief train of action potentials in rat hippocampal neurons in vitro, J. Neurophysiol., 63 (1990) $72-81$.

31 Womble, M.D. and Moises, H.C., Voltage-clamp analysis of cholinergic action in the basolateral amygdala, Soc. Neurosci. Abstr., 16 (1990) 1055.

32 Womble, M.D. and Moises, H.C., Muscarinic inhibition of M-current and a potassium leak conductance in neurones of the rat basolateral amygdala, J. Physiol., 457 (1992) 93-114. 